\title{
Evaluation and re-understanding of the global natural gas hydrate resources
}

\author{
Xiong-Qi Pang ${ }^{1,2} \cdot$ Zhuo-Heng Chen ${ }^{3} \cdot$ Cheng-Zao Jia ${ }^{1,4} \cdot$ En-Ze Wang $^{1,5} \cdot \mathrm{He}-$ Sheng Shi ${ }^{6} \cdot \mathrm{Zhuo}^{-} \mathrm{Ya} \mathrm{Wu}^{1,2} \cdot \mathrm{Tao} \mathrm{Hu}^{1,2}$. \\ Ke-Yu Liu ${ }^{7} \cdot$ Zheng-Fu Zhao ${ }^{1,8} \cdot$ Bo Pang $^{1,2} \cdot$ Tong Wang $^{1,2}$
}

Received: 1 February 2021 / Accepted: 17 February 2021 / Published online: 26 March 2021

(c) The Author(s) 2021

\begin{abstract}
Natural gas hydrate (NGH) has been widely considered as an alternative to conventional oil and gas resources in the future energy resource supply since Trofimuk's first resource assessment in 1973. At least 29 global estimates have been published from various studies so far, among which 24 estimates are greater than the total conventional gas resources. If drawn in chronological order, the 29 historical resource estimates show a clear downward trend, reflecting the changes in our perception with respect to its resource potential with increasing our knowledge on the NGH with time. A time series of the 29 estimates was used to establish a statistical model for predict the future trend. The model produces an expected resource value of $41.46 \times 10^{12} \mathrm{~m}^{3}$ at the year of 2050 . The statistical trend projected future gas hydrate resource is only about $10 \%$ of total natural gas resource in conventional reservoir, consistent with estimates of global technically recoverable resources (TRR) in gas hydrate from Monte Carlo technique based on volumetric and material balance approaches. Considering the technical challenges and high cost in commercial production and the lack of competitive advantages compared with rapid growing unconventional and renewable resources, only those on the very top of the gas hydrate resource pyramid will be added to future energy supply. It is unlikely that the NGH will be the major energy source in the future.
\end{abstract}

Keywords Natural gas hydrate Global gas hydrate resource $\cdot$ Conventional oil and gas resource $\cdot$ Renewable and sustainable energy $\cdot$ Trend analysis method

\section{Introduction}

Trofimuk assessed global natural gas hydrate (NGH) resources in 1973 with an in-place estimate of 3.02$3.09 \times 10^{18} \mathrm{~m}^{3}$ gas equivalent (Trofimuk et al. 1973). This vast energy resource in NGH was considered as a solution to future energy shortage (Arthur 2011; Wadham et al. 2012).

Edited by Jie Hao and Chun-Yan Tang

Xiong-Qi Pang

pangxq@cup.edu.cn

Zhuo-Heng Chen

Cheng-Zao Jia

1 State Key Laboratory of Oil and Gas Resources and Prospecting, Beijing 102249, China

2 College of Geosciences, China University of Petroleum (Beijing), Beijing 102249, China

3 Geological Survey of Canada, Natural Resources Canada, Calgary T2L 2A7, Canada
Afterward, other scholars and government agencies have conducted studies on this issue and obtained at least 29 different estimates with the maximum and minimum values varying by more than 10,000 times. Many still believed that NGH will be the main energy source in the future for the following reasons. (1) The estimated resource is enormous; among the 29 global estimates, 24 (Fig. 1b) are larger than the total conventional gas resource in place of $0.67 \times 10^{15}$

4 China National Oil and Gas Corporation, Beijing 100007, China

5 School of Earth \& Space Sciences, Peking University, Beijing 100871, China

6 Shenzhen Branch of China National Offshore Oil Corporation Ltd, Guangzhou 510240, China

7 CSIRO Earth Science and Resource Engineering, P. O. Box 1130, Bentley, WA 6102, Australia

8 Department of Geosciences and Natural Resource Management, University of Copenhagen, 1350 København, Denmark 

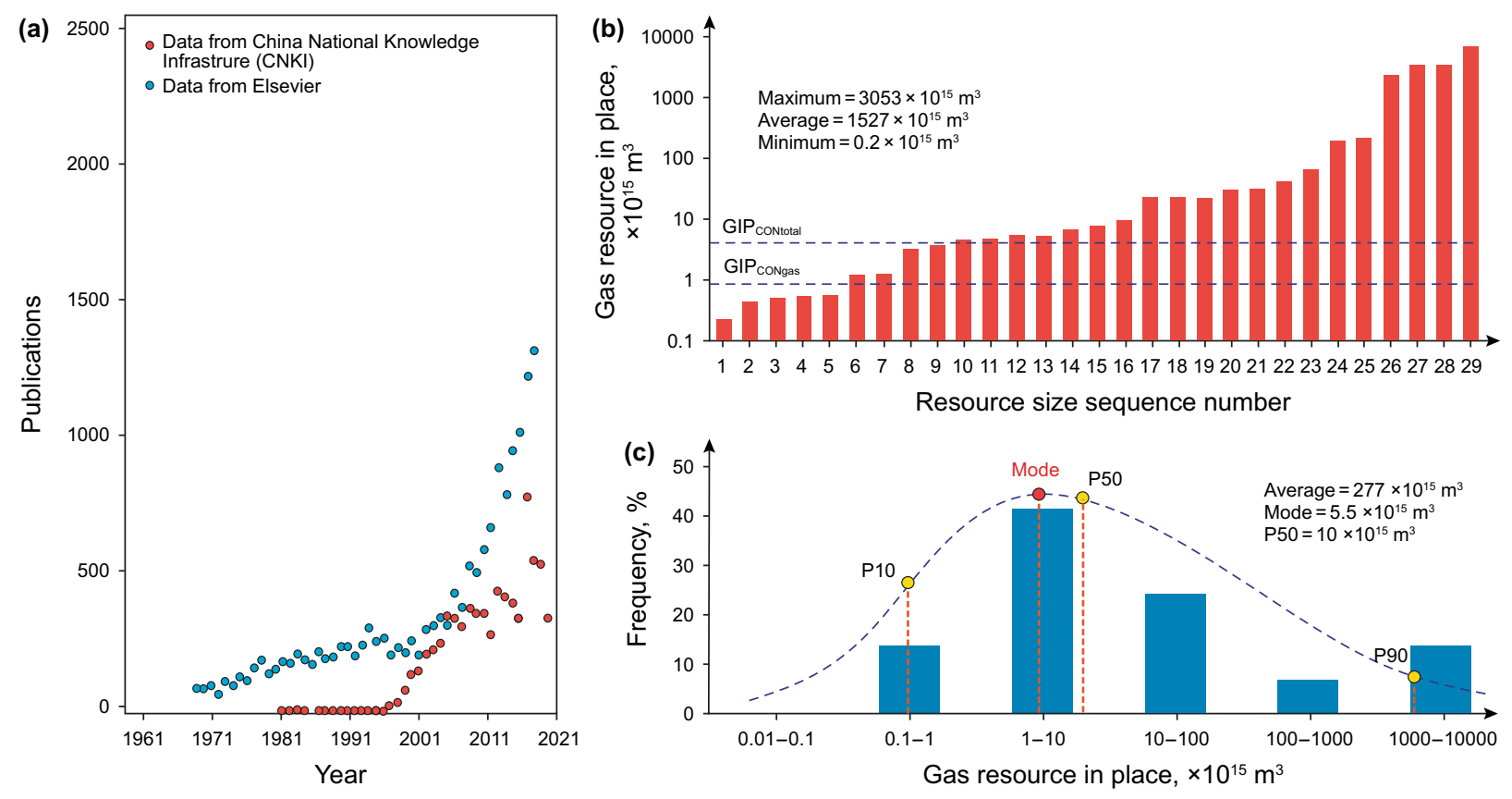

Fig. 1 Basic overview of global NGH researches. a Overview of the growth of papers related to NGH since 1970; b scale sequence distribution of global GIP estimates of NGH since 1973 around the world and statistical analysis parameters; $\mathbf{c}$ statistical distribution characteristics of global GIP estimates of NGH and relative parameters. GIP CONtotal $_{-}$Total conventional oil and gas resource in place, $4.1 \times 10^{15} \mathrm{~m}^{3}, \mathrm{GIP}_{\mathrm{CONgas}}-\mathrm{Total}$ conventional gas resource in place, $0.67 \times 10^{15} \mathrm{~m}^{3}$, data from reference (Zou et al. 2015)

$\mathrm{m}^{3}$ (Zou et al. 2015), whose average value, mode value, middle value and P50 value of 29 estimates are all higher than the total conventional gas resource (Fig. 1c); (2) The USA (Booth et al. 1996), Japan (Konno et al. 2017), Canada (Dallimore et al. 2005), India (Sain and Gupta 2012), Korea (Ning et al. 2012) and China (Yang et al. 2015) have launched research programs investigating the NGH as a type of potential energy resource since this century, the number of hydrate papers published every year has been increasing rapidly (Fig. 1a), indicating increased number of people involved in and investments to the research in gas hydrate. Following the Millik-5L-38 well production test of permafrost gas hydrate in northern Canada in 2002, several offshore production tests attempted to make technical breakthrough in producing the resource, and the Chinese company has successfully conducted a 60 -day production test in Shenhu Area of the South China Sea in 2017 in vertical well and completed a second round of 30-day test from a horizontal well in 2020 (Xinhua net 2020). (3) The Chinese government has listed it as a new mineral species and is ready to organize larger-scale exploration and development (Ministry of Natural Resources of China 2017).

Until now, there is no definite answer as whether or not NGH can be an alternative to replace conventional oil and gas in the future and the question is still being explored. However, the time series of 29 global estimates reveals a general trend with an indication that NGH may not become the major energy source replacing the diminishing petroleum resource in the future for three reasons. First, the 29 estimates vary up to five orders of magnitude, a reflection of lack of consensus on the character, mode of occurrence and a clear definition of the resource. Second, the pattern that the 29 estimates decrease gradually over time, reflecting increased knowledge of the resource, improved mapping methods and accumulated data for evaluation with time. Third, although those 29 global resource estimates were conducted by different scholars in different periods using different methods, they have one thing in common: The estimates converge with time gradually toward lower resource abundance with a range of variation equivalent to the uncertainty in petroleum resource assessment. Figure 2 illustrates resource "mapping" methods used and resulting estimates in different stages. In the initial stage, the prospective gas amount of NGH was estimated roughly based on the environments and depth in which they may occur, resulting in enormous resource volume. Later, studies found that the NGH can only be formed in some favorable environments, such as in marine and deep permafrost regions. In the second stage, resource estimate was constrained by the genetic mechanisms (Falenty et al. 2014) and formation conditions (Sloan 2003) of NGH, based on the sediment volume of the gas hydrate stable zone (GHSZ). It was realized that GHSZ is only a necessary condition, and the formation of NGH still requires gas source and other conditions (Dai et al. 


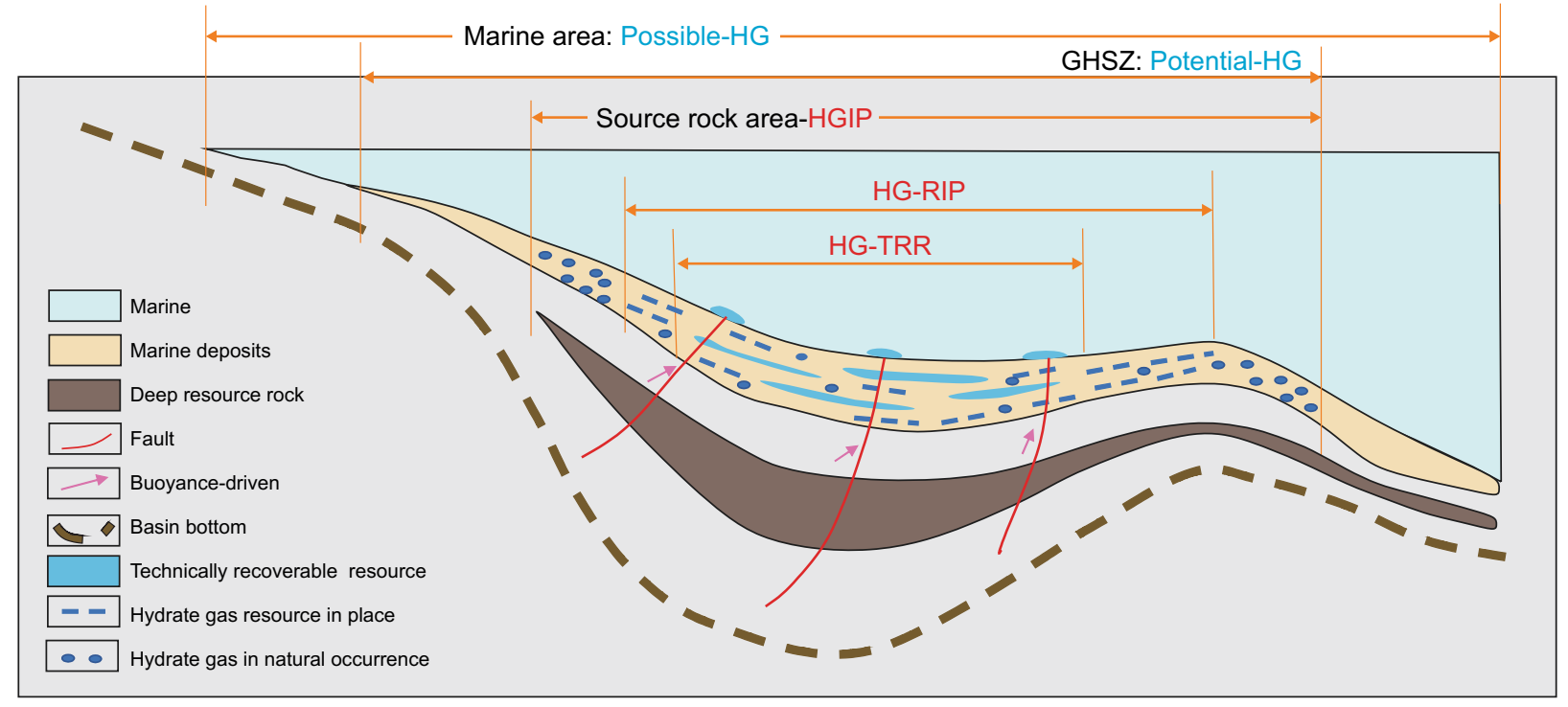

Fig. 2 NGH occurrence in different forms and their relationships to each other with major factors. Marine area is favorable for NGH (possible HG), but can only formed and distributed in gas hydrate stable zone (GHSZ) with high pressure and low temperature (potential HG). All hydrate gas in place (HGIP) exists in strata with gas coming from degradation of organic matter in shallow or deep source rocks; hydrate gas resource in place (RIP) and hydrate gas technically recoverable resource (TRR) are distributed in sandstone with high porosity or mudstone with fractures

2017). In the third stage, the in-place gas hydrate content (GIP) was estimated based on geophysical indication of the presence of natural gas-bottom simulating reflector (BSR) in the seismic profile. However, even small amount of free gas in GHSZ may cause significant geophysical anomalies, resulting in inclusion of areas of low concentration hydrate occurrence without economic significance in resource calculation (Boswell 2009; Boswell and Collett 2011). In the latest stage, the hydrate gas resource is evaluated with considering reservoir characteristics. Only those stored in high porosity in sandstone and the mudstones with fractures are considered technically recoverable resources. The deepening of such understanding and the continuously refining evaluation parameters led to the gradual reduction of the estimated results of NGH resources. For example, the global area extent of NGH in GHSZ decreases from an initial value of $220 \times 10^{4} \mathrm{~km}^{2}$ to current about $20 \times 10^{4} \mathrm{~km}^{2}$, the average thickness dropped from about $450 \mathrm{~m}$ to less than $50 \mathrm{~m}$, the average hydrate saturation in reservoir pores declined from nearly $100 \%$ to less than $40 \%$, etc., resulting in significant decreases in global NGH resources. All these changes reflect the continuous progress of human understanding of natural gas hydrate resources (Chong et al. 2016), some scholars introduced the concept of TRR for NGH resource assessment (Boswell 2009; Boswell and Collett 2011) and concluded that only a few concentrated NGH in high-porosity and permeable sandstone reservoirs or fractured muds are recoverable resources, and their estimated global GIP and TRR is about $(3-6) \times 10^{14} \mathrm{~m}^{3}$ and $3 \times 10^{14} \mathrm{~m}^{3}$, respectively.
As discussed above, the current NGH estimates are more reliable than previous results. It is possible to obtain more reliable results of the NGH by statistical analysis of the previous estimates. In this study, the trend analysis method was utilized to predict the future resources of the global GIP and TRR, and the corresponding trend values are determined as their objectively existing actual values when the variation of the 29 estimates is almost the constant in the future. This method can overcome problems in assessment, such as insufficient data, incorrect parameter values and immature understanding of the NGH in previous studies, and the estimated results are more representative and reliable than the results obtained by a single approach or several methods.

\section{Method and results}

\subsection{Trend analysis method principle}

Taking the previous 29 estimates of the global NGH since 1973 as a time series (Table 1), a statistical trend analysis is performed to project present and future resources simultaneously. Previous estimates were obtained by different scholars with different methods and techniques differing in levels and credibility. Before 1980, only a rough prospective and potential hydrate gas content of NGH was estimated by a few data. During 1980-2000, the GIP resource assessment was obtained by including BSR constraint from seismic data. During 2000-2010, the resource in place (RIP) was obtained 
Table 1 Estimated results and variation characteristics of global NGH resources by previous studies. V—volumetric method; $\mathbf{C}-$ comprehensive analysis method; D-particle organic carbon deposition rate method.

\begin{tabular}{|c|c|c|c|c|c|c|}
\hline No. & Methods & Data resources & Area, $\times 10^{6} \mathrm{~km}^{2}$ & Thickness, m & $\begin{array}{l}\text { GIP of } \\
\mathrm{NGH}, \\
\times 10^{15} \mathrm{~m}^{3}\end{array}$ & References \\
\hline 1 & $\mathrm{~V}$ & Doklady Akademii Nauk SSSR & 335.71 & 300 & 3053 & Trofimuk et al. (1973) \\
\hline 2 & $\mathrm{~V}$ & Doklady Akademii Nauk SSSR 225 & 360.2 & 300 & 1135 & Trofimuk et al. (1975) \\
\hline 3 & $\mathrm{~V}$ & Geologiyai Geofizika & 360.2 & 85 & 1573 & $\begin{array}{l}\text { Tsarev and Cherskiy et al. } \\
\text { (1977) }\end{array}$ \\
\hline 4 & V & Priroda 1 & 280.5 & 300 & 120 & Trofimuk et al. (1979) \\
\hline 5 & $\mathrm{~V}$ & Long-Term Energy Resources & - & - & 1550 & Nesterov and Salmanov, (1981) \\
\hline 6 & $\mathrm{~V}$ & Long-Term Energy Resources & 51.25 & 400 & 3.1 & McIver (1981) \\
\hline 7 & $\mathrm{~V}$ & $\begin{array}{l}\text { Proceedings of the Fifth II ASA Conference } \\
\text { on Energy Resources }\end{array}$ & - & & 15 & Trofimuk et al. (1983) \\
\hline 8 & $\mathrm{~V}$ & Chemical Geology & 10 & 500 & 40 & Kvenvolden (1988) \\
\hline 9 & $\mathrm{~V}$ & Annual Review of Energy & 62.4 & 500 & 20 & MacDonald (1990) \\
\hline 10 & $\mathrm{~V}$ & Global Biogeochemical Cycles & $36.3-54.7$ & $379 \sim 453.4$ & 26.4 & Gornitz and Fung (1994) \\
\hline 11 & $\mathrm{~V}$ & Journal of Geophysical Research & 59.6 & 277 & 0.48 & Harvey and Huang (1995) \\
\hline 12 & $\mathrm{~V}$ & Science & 10.5 & 400 & 6.8 & Holbrook et al. (1996) \\
\hline 13 & $\mathrm{~V}$ & Nature & 10.5 & 400 & 15 & Dickens et al. (1997) \\
\hline 14 & $\mathrm{~V}$ & Penn Well & - & - & 15 & Makogon (1997) \\
\hline 15 & $\mathrm{C}$ & $\begin{array}{l}\text { Proceedings of the National Academy of } \\
\text { Sciences }\end{array}$ & - & - & 21 & Kvenvolden (1999) \\
\hline 16 & $\mathrm{~V}$ & Organic Geochemistry & 17.5 & 400 & 4 & Dickens (2001) \\
\hline 17 & $\mathrm{~V}$ & Russian Geology and Geophysics & 35.7 & 2.8 & 0.21 & Soloviev (2002) \\
\hline 18 & $\mathrm{~V}$ & Geology & 7 & 300 & 4 & Milkov et al. (2003) \\
\hline 19 & $\mathrm{~V}$ & Earth-Science Reviews & 4.5 & 300 & 2.5 & Milkov (2004) \\
\hline 20 & $\mathrm{D}$ & Earth and Planetary Science Letters & 13.1 & 300 & 5.7 & Buffett and Archer (2004) \\
\hline 21 & $\mathrm{~V}$ & Energy \& Fuels & - & & 115.4 & Klauda and Sandler (2005) \\
\hline 22 & $\mathrm{~V}$ & Marine Geology and Quaternary Geology & & & 0.397 & Ge et al. (2005) \\
\hline 23 & $\mathrm{D}$ & $\begin{array}{l}\text { Proceedings of the National Academy of } \\
\text { Sciences }\end{array}$ & 13.1 & 300 & 3.4 & Archer et al. (2009) \\
\hline 24 & $\mathrm{D}$ & Geochimica Et Cosmochimica Acta & - & & 0.5 & Burwicz (2011) \\
\hline 25 & $\mathrm{C}$ & Energy \& Environmental Science & - & & 0.45 & Boswell and Collett (2011) \\
\hline 26 & $\mathrm{D}$ & Energies & 147 & 300 & 1.0 & Wallmann et al., (2012) \\
\hline 27 & $\mathrm{D}$ & Biogeosciences & 26 & 300 & 1.05 & Piñero et al., (2013) \\
\hline 28 & $\mathrm{C}$ & Advances in New and Renewable Energy & - & & 5 & Cong et al. (2014) \\
\hline 29 & $\mathrm{D}$ & Global Biogeochemical Cycles & - & & 3.5 & Kretschmer et al. (2015) \\
\hline
\end{tabular}

by seismic profile data and drilling wells. After 2010 , the TRR resource was evaluated by using the recovery factors obtained through laboratory physical and numerical simulations (Konno et al. 2014). This implies that the level and reliability of the later estimated results is much higher than the previous estimates.

The 29 estimates of the global NGH were fitted to an empirical model as a function of time (Year) as shown in Fig. 3a. Before 1980, the global estimates of NGH were in the order of $8 \times 10^{18} \mathrm{~m}^{3}$, declining gradually to around $7.0 \times 10^{14} \mathrm{~m}^{3}$ in $2010 \mathrm{~s}$, about four orders of magnitude less. The drastic drop is due to improved understanding of the nature of $\mathrm{NGH}$ occurrence and much reliable volumetric parameters validated by drilling results, such as occurrence area, net reservoir thickness, saturation and others. Since 2010, the decline rate of estimated results has slowed down significantly and is nearly constant in 2050. In this study, the corresponding trend value at 2050 is roughly regarded as the theoretical maximum value of estimated global RIP of NGH.

\subsection{Estimate of global RIP and TRR}

Based on the statistical trend analysis model, the final simulation of the global GIP and TRR of NGH at 2020 and 2050 


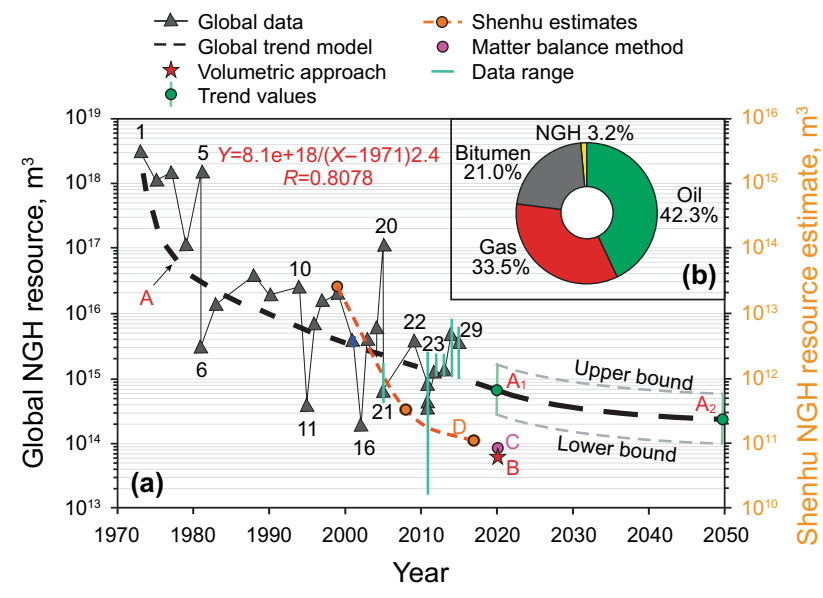

Fig. 3 Estimated results of the global resource of NGH by trend analysis method and compared to other results. a Historical global GIP estimates of NGH showing a general tendency of decreasing resource with time (A), superimposed with fitted statistical trends to project future estimates, projected resource estimates of mode values for RIP of NGH at 2020 and 2050 and their uncertainty range from the statistical trend analysis are added to the plot $\left(\mathrm{A}_{1}, \mathrm{~A}_{2}\right)$. The estimate of mode value for RIP of NGH from volumetric approach is shown in red star (B), and the average value for the RIP of NGH from matter balance approach is shown in pink dot $(\mathrm{C})$. The historical resource estimates for GIP of NGH from 1999 to 2017 in Shenhu area of South China Sea are plotted to show the learning curve in orange dotted line (D). b The proportion of global TRR of NGH in the total amount of four types of conventional oil and gas resources is shown in the pie chart at the upper right

are conducted. The recovery parameters obtained by physical simulation laboratory are used in the calculation of the TRR, varying from $15 \%$ to $70 \%$ with a mode of $30 \%$. The projected mode of global RIP of NGH resource is $711.20 \times 10^{12} \mathrm{~m}^{3}$ at 2020, and the projected RIP at 2050 ranges from 45 (F90) to 367 (F10) $\times 10^{12}$ with a mode of $148.22 \times 10^{12} \mathrm{~m}^{3}$ (Fig. $4 \mathrm{a}$ and b). The projected TRR at 2050 ranges from 28 (F90) to 145 (F10) with a mode of $41.46 \times 10^{12} \mathrm{~m}^{3}$ (Fig. $4 \mathrm{c}$ and d), indicating the NGH resources will continue to decline in the next 30 years, from 2020 to 2050 ( $A_{1}$ and $A_{2}$ in Fig. 3a). As NGH exploration and research results are increasingly disclosed to the public, it will guarantee better distinguishing potential economic resources from the entire NGH occurrence, allowing the estimates being more consistent, realistic and less uncertain. However, as suggested by the resource estimate patterns during the last 20-year NGH exploration in the Shenhu Area (Orange dotted line D in Fig. 3a), it may take decades to achieve this effect. The projected trend of the global NGH resources from 2020 to 2050 also supports a long time period of learning. So far, $1362.0 \times 10^{12} \mathrm{~m}^{3}$ gas equivalent of global TRR of conventional oil and gas has been found worldwide, including $595.0 \times 10^{12} \mathrm{~m}^{3}$ gas equivalent of oil and $470.5 \times 10^{12}$ $\mathrm{m}^{3}$ gas in normal traps, and $296.5 \times 10^{12} \mathrm{~m}^{3}$ gas equivalent of bitumen and heavy oil in reformed traps. The TRR of NGH estimated in trend analysis accounted for only $3.2 \%$ of all these conventional resources, as shown in Fig. 3 b.

\section{Reliability validation-compared with volumetric method}

The latest drilling results, volumetric methods and Monte Carlo technique were combined to evaluate the global NGH resources, and the result was then compared with that obtained by trend analysis, which were both tested and validated mutually.

\subsection{Volumetric method principle}

For a proven NGH reservoir, the GIP and RIP are related to hydrate distribution area $(A)$, average thickness $(H)$, porosity $(\varnothing)$, gas hydrate saturation $\left(S_{\text {gh }}\right)$, gas volume conversion coefficient $\left(B_{\mathrm{gh}}\right)$ and conversion coefficient $\left(K_{\mathrm{R}}\right) . K_{\mathrm{R}}$ is the ratio of enriched NGH resource to total NGH resource, and the enriched NGH resource is identified by criteria of $\sum H_{i}>$ $2 \mathrm{~m}, S>10 \%$, and $\emptyset>15 \%$; here, $\sum H_{i}$ refers to accumulative net thickness of the target layers $(i)$ with enriched NGH, and the GIP and RIP calculations are expressed in Eqs. 1 and 2. After obtaining the relative data, the TRR of the NGH was calculated according to Eq. 3. After converting the RIP and TRR in the hydrate reservoirs into the ratios of resources for per unit volume in GHSZ, the global RIP and TRR can be evaluated by multiplying the total volume of GHSZ in different regions with these two ratios.

$\mathrm{GIP}=A \times H \times \phi \times S_{\mathrm{gh}} \times B_{\mathrm{gh}}$

$\mathrm{RIP}=K_{\mathrm{R}} \times \mathrm{GIP}$

$\mathrm{TRR}=K_{\mathrm{R}} \times \mathrm{RIP}$

The above calculation is too crude because it does not consider the formation conditions of NGH in different GHSZ. In this study, this method is further improved by considering both GHSZ volume and formation conditions using probability distributions. The relevant geological model and calculation equations are shown in Fig. 2 and Eqs. 4-10. Equation 4 is used to calculate the global possible hydrate gas content, and mainly considering the rock volume in GHSZ area, $B_{\mathrm{gh}}$ is hydrate gas volume coefficient in the earth's surface; Eq. 5 is used to calculate the GIP of $\mathrm{NGH}$, further considering the gas source conditions, and $K_{\text {source }}$ refers to the ratio of source rock area to GHSZ area; Eq. 6 is used to calculate the global migration gas content 

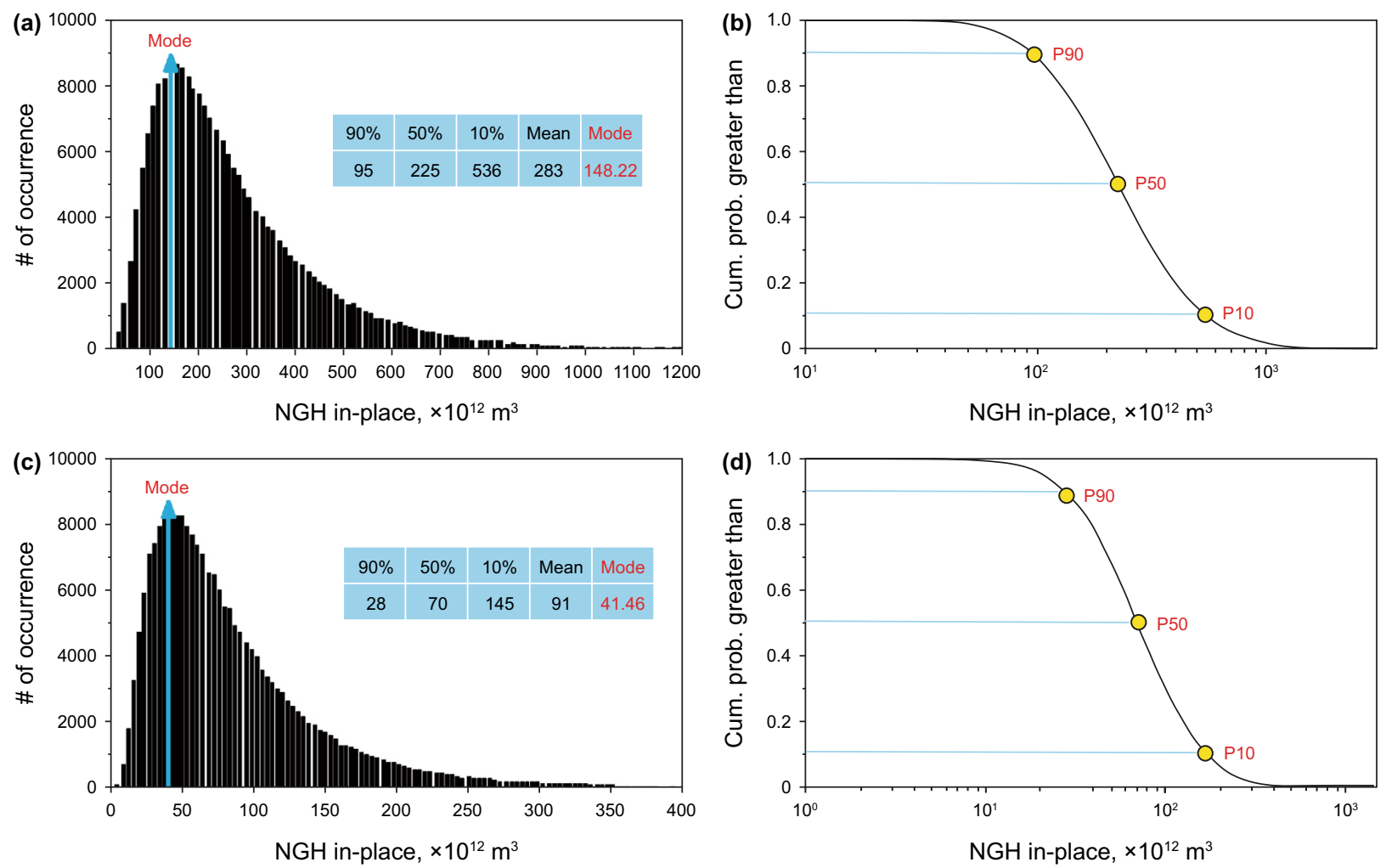

Fig. 4 Estimated results of the global RIP of NGH by trend analysis method, indicating statistical distributions of RIP and TRR for global NGH resources from statistical trend analysis of 29 previous estimates at the year of 2050. a RIP histogram; b RIP cumulative probability; $\mathbf{c}$ TRR histogram; d TRR cumulative probability

in place (MIP), the area with no gas expulsion from source rocks (Pang et al. 2005) is left out from favorable area, and $K_{\text {migra }}$ refers to the ratio of area with gas expulsion from effective source rocks to all source rock area. Eq. 7 is used to calculate the global accumulated gas content in place (AIP) of NGH, and further considering the hydrate accumulation conditions, $K_{\text {play }}$ refers to the ratio of reservoir volume to all rock volume in area with effective source rocks or the product of plane reservoir area ratio $K_{\text {play-A }}$ and vertical thickness ratio $K_{\text {play-H}}$; Eqs. 8 and 9 are used to calculate the global RIP of NGH, only considering the accumulated NGH with enrichment degree greater than specified requirement, and $K_{\text {enrich }}$ refers to the ratio of enriched resource to all accumulated resource; and Eq. 10 is used to calculate global TRR of $\mathrm{NGH}$, and considering the resource favorable for exploitation currently, $K_{\text {recov }}$ refers to the ratio of recoverable NGH resource to all enriched NGH resources.

$Q_{\text {possible }}=A_{\mathrm{GHSZ}} \times H_{\mathrm{GHSZ}} \times \phi \times S_{\mathrm{gh}} \times B_{\mathrm{gh}}$

$\mathrm{GIP}=K_{\text {source }} \times Q_{\text {possible }}$

$\mathrm{MIP}=K_{\text {migra }} \times \mathrm{GIP}$
$\mathrm{AIP}=K_{\text {play }} \times \mathrm{MIP}$

$\mathrm{RIP}=K_{\text {enrich }} \times \mathrm{AIP}$

$\mathrm{RIP}=K_{\text {enrich }} \times K_{\text {play }} \times K_{\text {migra }} \times K_{\text {source }} \times A_{\text {GHSZ }} \times H \times \phi \times S_{\text {gh }} \times B_{\text {gh }}$

$$
\begin{aligned}
\mathrm{TRR}= & K_{\text {recov }} \times K_{\text {enrich }} \times K_{\text {play }} \times K_{\text {migra }} \times K_{\text {source }} \\
& \times A_{\mathrm{GHSZ}} \times H \times \phi \times S_{\text {gh }} \times B_{\text {gh }}
\end{aligned}
$$

The reservoir volumetric parameters are determined from statistics of well-studied NGH reservoirs and production test data, mainly from Shenhu Area in South China Sea (Fig. 5) and permafrost region of the Beaufort-Mackenzie Basin in Canada (Katsube et al. 2005). The history of the NGH resource evaluation in the Shenhu Area is an epitome of the global NGH assessment. The Shenhu site in the Pearl River Mouth Basin, South China Sea, covers about $3000 \mathrm{~km}^{2}$. In 1999, the first NGH resource assessment was conducted based on BSR anomalies from seismic survey and obtained an overly optimistic prospective gas content of $29 \times 10^{12} \mathrm{~m}^{3}$. During 1999-2007, 5 exploration wells were drilled and a 
resource reevaluation based on newly drilled data lead to a reduced gas content of $199 \times 10^{9} \mathrm{~m}^{3}$. In the following decade, 14 more wells were drilled and 60-day production test was conducted in 2017, the updated GIP resource was further reduced to one-third of the previous estimate, with a mode of $66 \times 10^{9} \mathrm{~m}^{3}$. The estimate shrunk almost three orders of magnitude compared with the first assessment. The Mallik is one of the best-studied NGH accumulations in a permafrost environment worldwide. The NGH studies in Mallik site were carried out in the 1980 and continued to 2010's. The Mallik NGH accumulation occurs below thick permafrost and overlays directly on a free gas field sourced from deep thermal genetic gas of the basin. A basin wide study in the Beaufort-Mackenzie Basin (BMB) based on petrophysical logs from 251 oil and gas exploration wells showed that, although the NGH occurs in 122 wells (50\%), only 7 contain net thickness greater than 5 meters, accounting for $<3 \%$ of the total wells studied (Osadetz and Chen 2010).

Based on the analysis of the above examples, NGH resource coefficient was determined as $18 \%$, and the RIP and TRR per cubic kilometer in GHSZ are estimated as $0.12 \times 10^{8} \mathrm{~m}^{3} / \mathrm{km}^{3}$ and $0.036 \times 10^{8} \mathrm{~m}^{3} / \mathrm{km}^{3}$, respectively. When the areal extent of global GHSZ is determined to be about $50 \times 10^{6} \mathrm{~km}^{2}$ and $350 \mathrm{~m}$ in thickness, the corresponding global total RIP and TRR of NGH are $210 \times 10^{12} \mathrm{~m}^{3}$ and $63 \times 10^{12} \mathrm{~m}^{3}$ by analogy, and the TRR accounts for $4.4 \%$ of total conventional oil and gas resources.

Formation conditions of global NGH in different regions differ greatly from the drilling results, and the mode values and variation ranges of these parameters are finally determined after analyzing the formation conditions of NGH and the variation of essential parameters about NGH reservoirs (Table 2). Finally, Eqs. 9 and 10 as well as Monte Carlo technology were utilized to calculate the distributions of global RIP and TRR of NGH with different probability. This method can also be used to evaluate the potential resources of NGH in any specific sedimentary basin in the world.

\subsection{Estimates of global RIP and TRR}

The statistic results of parameters from the Shenhu Area, BMB and other well-studied NGH sites, coupled with governing principles of deposition of source and reservoir rocks in sedimentary basins, as well as those parameters including area, thickness of the GHSZ in the world are used to evaluate the global RIP and TRR of NGH resource. The volumetric method combined with Monte Carlo simulation yielded distributions of RIP and TRR of NGH resource, respectively (Fig. 6); the global RIP estimates range from $45 \times 10^{12} \mathrm{~m}^{3}$ (F90) to $367 \times 10^{12} \mathrm{~m}^{3}$ (F10) with a mode of $64.51 \times 10^{12} \mathrm{~m}^{3}$ (Figs. $6 \mathrm{a}$ and $5 \mathrm{~b}$ ), and the TRR estimates range from $14 \times 10^{12} \mathrm{~m}^{3}$ (F90) to $119 \times 10^{12} \mathrm{~m}^{3}$ (F10) with a mode of $22.09 \times 10^{12} \mathrm{~m}^{3}$ (Fig. $6 \mathrm{c}$ and d). The TRR of NGH obtained by the volumetric method accounts for $1.6 \%$ to $4.4 \%$ of the total conventional oil and gas resources, respectively.

\section{Reliability validation-compared with matter balance approach}

\subsection{Mass balance method principle}

At least 13 NGH accumulations have been extensively studied around the world (Table 3). Methane carbon isotope data from samples in the 13 sites show that all $\delta^{13} \mathrm{C}_{1}$ values are $<-30 \%$, indicative of organic origin. Among them, 55\% is of biogenic origin with $\delta^{13} \mathrm{C}_{1} \leq-55 \%$, and $20 \%$ is thermogenic with $\delta^{13} \mathrm{C}_{1}$ varying between $-55 \%$ and $-30 \%$; and the other $25 \%$ show signatures of mixed biogenic and thermogenic origins having $\delta^{13} \mathrm{C}_{1}$ ranging from $-80 \%$ o to $-30 \%$. Biodegradation and thermal degradation provide about $60 \%$ and $40 \%$ of natural gas hydrate, respectively, indicating homologous with conventional and unconventional oil and gas in petroliferous basins (Dai et al. 2017).

The geochemical characteristics of NGH indicate that the total potential resource of NGH cannot exceed the total amount of oil and gas generated by the organic matter in the sedimentary basin before entering the active source rock depth limit (Pang et al. 2020a), expressed quantitatively as in Eq. 11 and Fig. 7a. The NGH enrichment occurs in the sandstones with high porosity and fractured mudstones, showing that the gas within NGH is generated and expelled from both biogenic and thermogenic source rocks, migrated through fault, unconformity or reservoir layers, and accumulated in reservoirs with high porosity and permeability. This process is mainly driven by the buoyancy, and the enriched NGH resource is controlled by the gas amount expelled from all source rocks above buoyance-driven hydrocarbon accumulation depth (Pang et al. 2021). These findings suggest that the total potential resources of all kinds of oil and gas resource, including NGH, cannot exceed the total amount of oil and gas expelled from the source rocks, quantitatively expressed as in Eq. 12 and Fig. 7a2/a3. Previous studies show that NGH is a special type of conventional oil and gas reservoir, whose migration and enrichment are dominated by buoyancy (Zhang et al. 2017), so it can only be formed in stratigraphic area above the BHAD. Therefore, it can be inferred that their maximum potential resource cannot exceed the hydrocarbon amount expelled from source rocks above the BHAD in the petroliferous basin, which can be quantitatively represented by Eq. 13 and Fig. 7a2. In six representative petroliferous basins of China, including the Tarim, Junggar, Ordos, Sichuan, Bohai Bay and Songliao Basins, the amount of oil and gas expelled from their source rocks before buried under the BHAD accounts for about $10.8 \%$ of the total amount of generated oil and gas, which theoretically represents the maximum potential limit of NGH resources. The formation and distribution of various oil and 

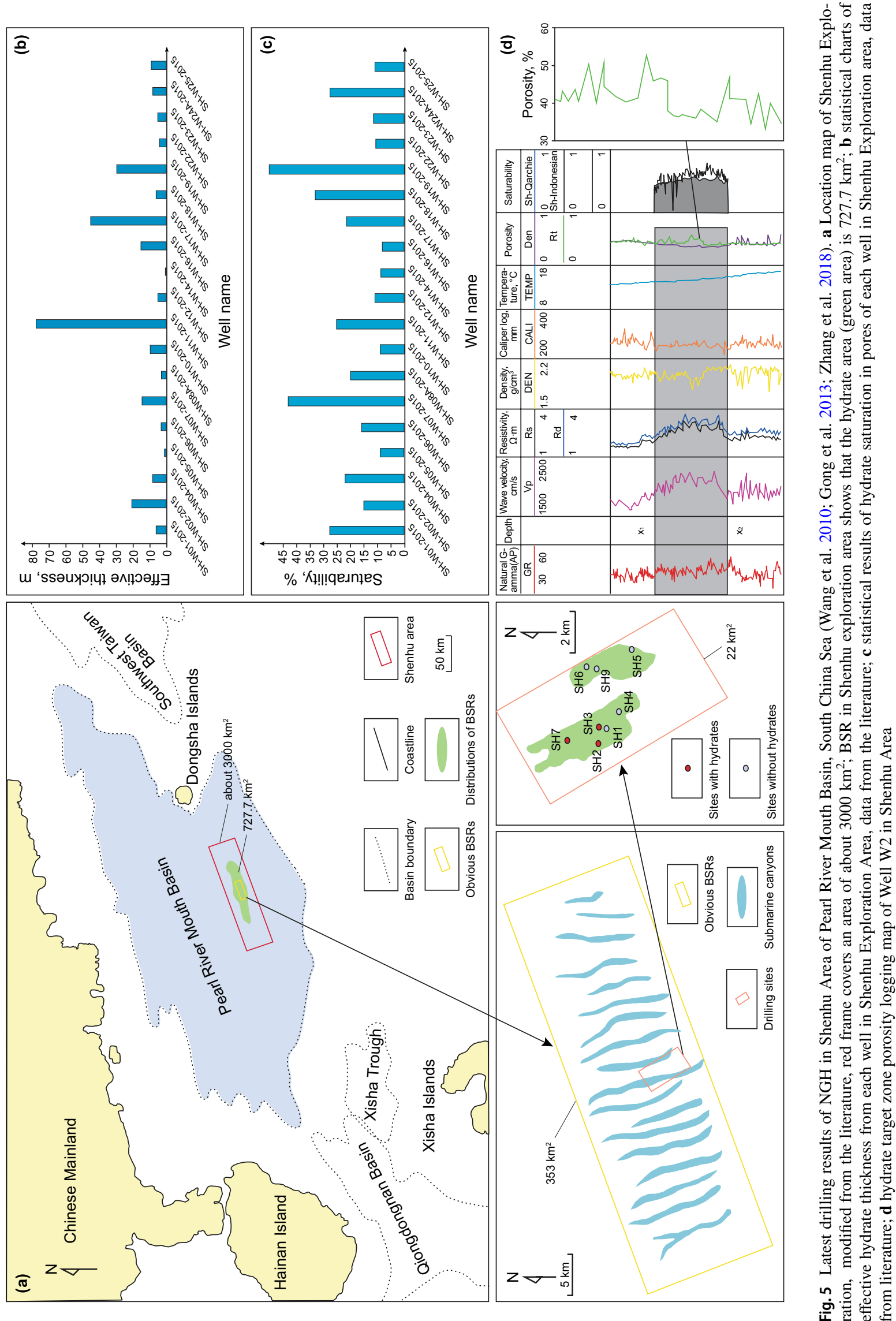
gas resources in petroliferous basins and their relationship with the dynamic boundaries and hydrocarbon dynamic fields can be characterized by a joint model in Fig. 7b (Pang et al. 2020b). The stratigraphic area above the BHAD is a free dynamic field (F-HDF) for oil and gas migration and accumulation dominated by buoyancy, forming three kinds of conventional oil and gas resources with different characteristics, including normal trapped oil and gas resources, reformed heavy oil and bitumen resources, and solid NGH resources. This imply that the potential NGH resource cannot exceed the total amount of all kinds of conventional oil and gas resources in the F-HDF, and the total potential NGH resource can be roughly estimated according to the percentage of GHSZ volume in the volume of free dynamic field, expressed quantitatively as in Eqs. 14 and 15.

$Q_{\mathrm{NGH}}<Q_{\mathrm{p}}$

$Q_{\mathrm{NGH}}<Q_{\mathrm{e}}$

$Q_{\mathrm{NGH}}<Q_{\mathrm{e}}^{a}$

$Q_{\mathrm{NGH}}=\left(V_{\mathrm{GHSZ}} / V_{\mathrm{F}-\mathrm{HDF}}\right) \times Q_{\mathrm{conv}}$

$R_{\mathrm{NGH}}=V_{\mathrm{GHSZ}} / V_{\mathrm{F}-\mathrm{HDF}} \approx\left(A_{\mathrm{GHSZ}} \times H_{\mathrm{GHSZ}}\right) /\left(A_{\mathrm{F}-\mathrm{HDF}} \times H_{\mathrm{F}-\mathrm{HDF}}\right)$

where $Q_{\mathrm{NGH}}$-total potential NGH resource; $Q_{\mathrm{p}}$-total generated hydrocarbon amount, including the hydrocarbon amounts remained in source rocks and expelled from source rocks; $Q_{\mathrm{e}}^{\mathrm{a}}$-hydrocarbon amount expelled from source rocks; $Q_{\mathrm{e}}^{\mathrm{a}}$-hydrocarbon amount expelled from source rocks in the F-HDF above the BHAD; $V_{\mathrm{GHSZ}}$ - stratigraphic volume of gas hydrate stable zone; $V_{\mathrm{F}-\mathrm{HDF}}-$ stratigraphic volume of free hydrocarbon dynamic field above the BHAD; $R_{\mathrm{NGH}}$-ratio of total NGH resources to the total oil and gas resources in F-HDF; $A_{\mathrm{GHSZ}}$ and $H_{\mathrm{GHSZ}}$-average area and thickness of GHSZ, respectively; and $A_{\mathrm{F}-\mathrm{HDF}}$ and $H_{\mathrm{F}-\mathrm{HDF}}-$ average and thickness of F-HDF, respectively.

\subsection{Estimates of global RIP and TRR}

According to the original data of 29 groups of previous estimates, it is found that the average values of GHSZ area $\left(A_{\mathrm{GHSZ}}\right)$ used by different scholars range from $50 \times 10^{6} \mathrm{~km}^{2}$ to $68 \times 10^{6} \mathrm{~km}^{2}$, and the average values of GHSZ thickness $\left(H_{\mathrm{GHSZ}}\right)$ range from $324 \mathrm{~m}$ to $400 \mathrm{~m}$. Based on the statistic results of 52,926 conventional oil and gas reservoirs (IHS, 2016) in the world, the average areas of free hydrocarbon dynamic field (F-HDF) in petroliferous basins $\left(A_{\mathrm{F}-\mathrm{HDF}}\right)$ range from 162 to $245 \times 10^{6} \mathrm{~km}^{2}$, and the average buried depths $\left(H_{\mathrm{F}-\mathrm{HDF}}\right)$ range from $2500 \mathrm{~m}$ to $3000 \mathrm{~m}$. In accordance with these data and Eq. 15, it is estimated that the ratio
$\left(R_{\mathrm{NGH}}\right)$ of global NGH resources to total conventional oil and gas resources varies between $2.2 \%$ and $6.7 \%$. As only gas hydrates can be formed in GHSZ, this ratio varies from about $1.1 \%$ to $3.4 \%$ with an average of $2.3 \%$, the global TRR of NGH resource is derived to be $15-46 \times 10^{12} \mathrm{~m}^{3}$ based on Eq. 14, and the global RIP of NGH resources is $(44.0-134.8) \times 10^{12} \mathrm{~m}^{3}$.

In petroliferous basins, more than $90 \%$ of NGH are dispersed in mud or mudstone with hydrate saturation less than 5\%. Even for those accumulated resources in reservoir layers, only small part of them can become recoverable resource with porosity $>12 \%$, saturation $>20 \%$ and accumulative thickness $>2 \mathrm{~m}$. The drilling results reveal that these highly enriched NGH resources account for about $20 \%$ of total accumulated NGH in reservoir layers. In Shenhu Area of China, it is about $18 \%$, and in the world, it is about 22\% (Boswell 2009; Boswell and Collett 2011), implying the resource ratio coefficient of NGH is $20 \pm 2 \%$ (Fig. 8a). The proportion of NGH in total conventional oil and gas resources varied from $1.1 \%$ to $4.4 \%$, with an average of less than $3 \%$, and their proportion in total oil and gas resources was even lower (Fig. 8b). The total potential resources of unconventional oil and gas (shale oil and gas, tight oil and gas) are estimated to be about 3-5 times that of conventional oil and gas resources (McGlade et al. 2013; Zou et al. 2015); thus, it is reasonable that the NGH resources account for less than $1 \%$ of all kinds of oil and gas resources in petroliferous basins.

\section{Discussions and implications}

The mode value of $41 \times 10^{12} \mathrm{~m}^{3}$ for TRR of global NGH resource obtained by trend analysis method accounts for $3.2 \%$ of the TRR of global conventional oil and gas resource $\left(1403 \times 10^{12} \mathrm{~m}^{3}\right.$ gas equivalent). It is in close agreement with the results obtained by the volumetric method and mass balance method, much less than previous estimates. The three kinds of results from three different methods and their average comprehensive results are listed in Table 4. The comprehensive TRR for global NGH varies from $(15-63) \times 10^{12} \mathrm{~m}^{3}$, whose ratios to the total conventional oil and gas resource changes from $1.1 \%$ to $4.4 \%$, based on the world oil and gas consumption level of $7.6 \times 10^{12} \mathrm{~m}^{3}$ gas equivalent in 2017 (BP 2018), can only meet demands of our society for 2 to 8 years.

Evaluation results of three different methods reflect the limitation of NGH resources from three different aspects. The matter balance method reveals the limitation of the potential NGH resource in terms of the genetic mechanism, and the theoretical calculation results show that the potential NGH resource cannot exceed $3.4 \%$ of the total conventional oil and gas resources in F-HDF or $1 \%$ of the total oil and gas 


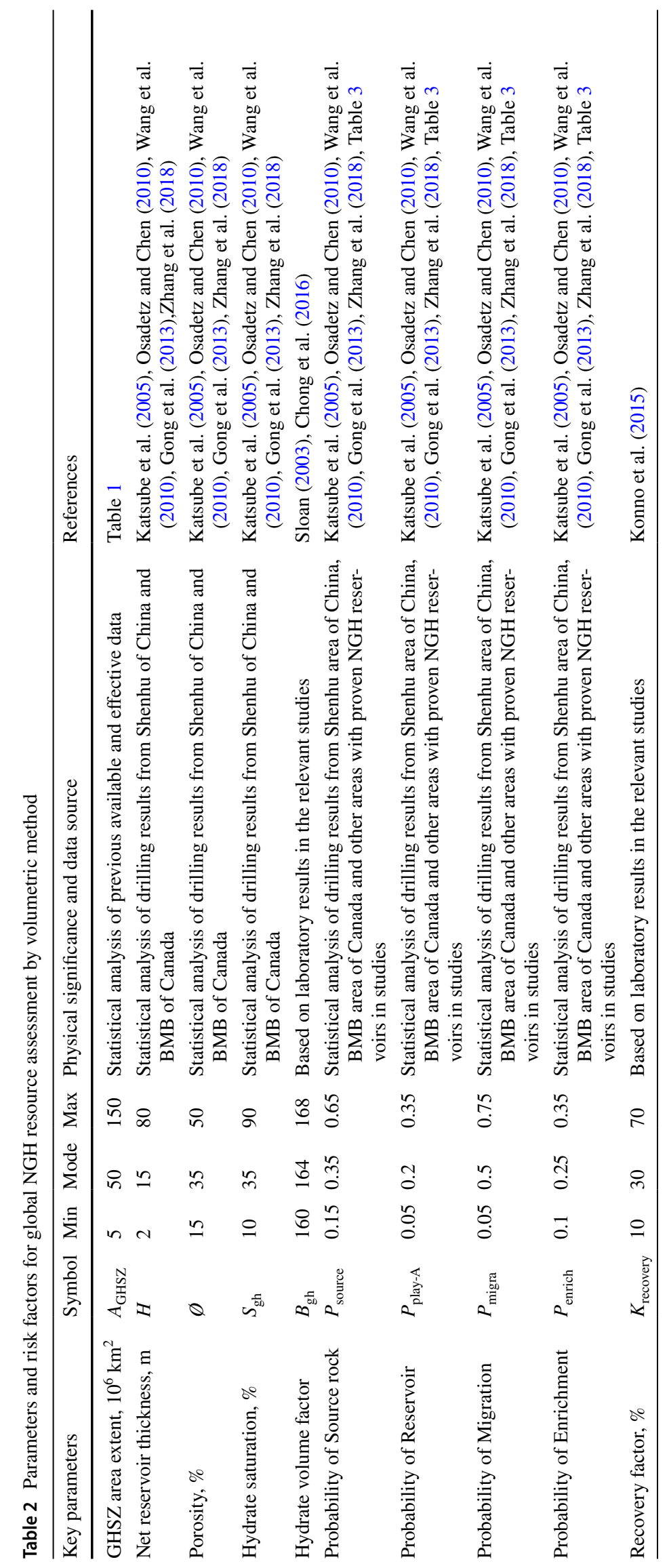



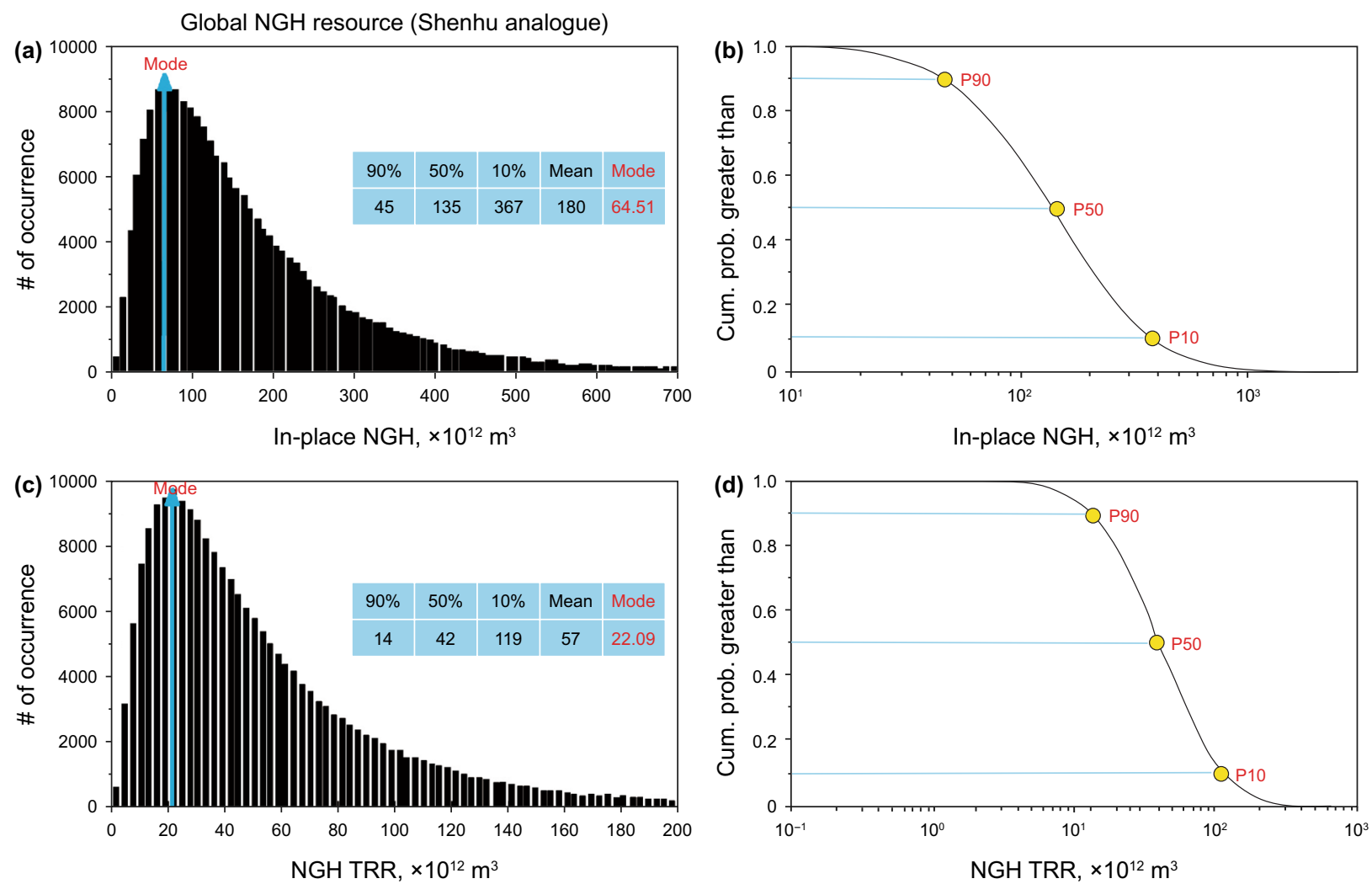

Fig. 6 Estimated results of RIP of global NGH by volumetric method, indicating the statistical distributions of results for GIP and TRR by reservoir volumetric approach using analogues from well-studied gas hydrate accumulations in the world: Shenhu Area of China in marine and Mallik area of Canada in permafrost. a GIP histogram; b GIP cumulative probability; $\mathbf{c}$ TRR histogram; $\mathbf{d}$ TRR cumulative probability

resources in the basin. Volumetric method reveals the limitation of potential NGH resource from exploration practice and drilling results, the Shenhu exploration area in China and the MBM area in Canada are the most favorable areas for gas hydrate accumulation in the ocean and the permafrost region, respectively, and the results obtained by comparing them with other regions in the world represent the upper limit of the potential NGH resource to some extent. As the results obtained by trend analysis method eliminate the estimate differences caused by varied methods, data, technology and purposes in previous studies, it is more representative, more predictive and closer to the objective reality than any other results.

In comparison, unconventional oil and gas resources have much great potential, which are replacing conventional oil and gas resources in North America, and will account for over $65 \%-75 \%$ of the total annual energy consumption before 2050 (Schelly 2016). Besides, the world annual renewable energy production, such as nuclear, solar, wind, geothermal and hydropower, accounted for $15.1 \%$ in total energy consumption in 2017, and it will reach $30 \%$ by 2050 (Energy Information Administration 2010). Obviously, it is difficult for the NGH to compete with other alternative energy by 2050 .

Although Japan and China have made progresses in marine NGH production tests, and the USA and Canada have made achievements in permafrost sites, there is still a long way to achieve commercial production status. The current costs of the NGH production are much higher than that of conventional oil and gas reservoirs, and significantly higher than those from unconventional oil and gas reservoirs as additional energy inputs are required to disassociate NGH prior to production. Harsh environments of deep water or remote permafrost region and associated geohazards with dissociation of NGH bring further challenges. In addition, the NGH exploitation may have environmental consequences. Methane is one of the most potent greenhouse gasses with capacity of absorbing heat about 21 times of carbon dioxide. The NGH dissociation in production, hydrate structural transition throughout differentiation and critical pressure change of free-gas reservoirs below NGH provinces could lead to methane leakage, causing greenhouse effect (Hope 2006). Increased concentration of methane in water due to NGH production could reduce water density, causing marine acidification, and the NGH dissociation in 


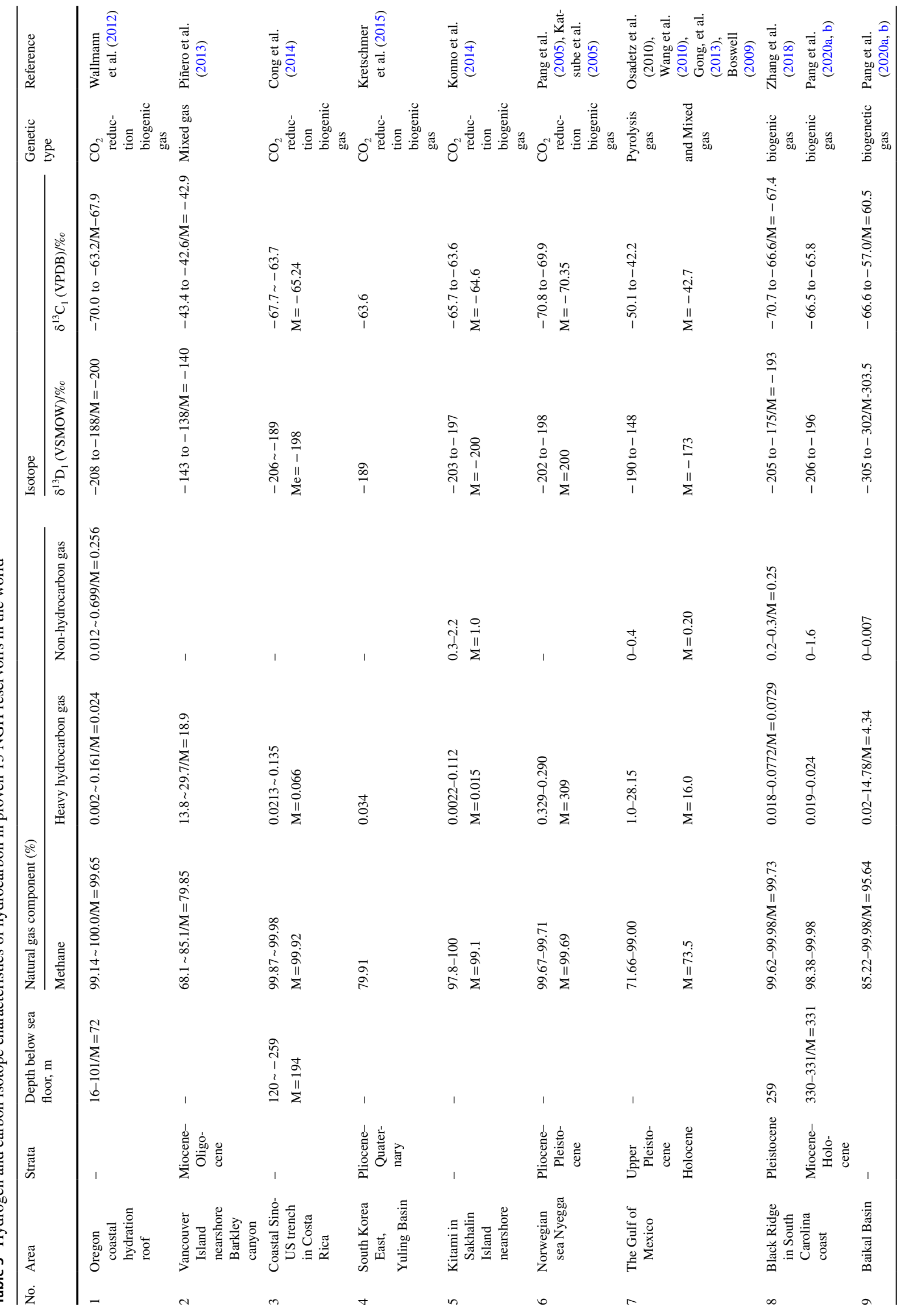




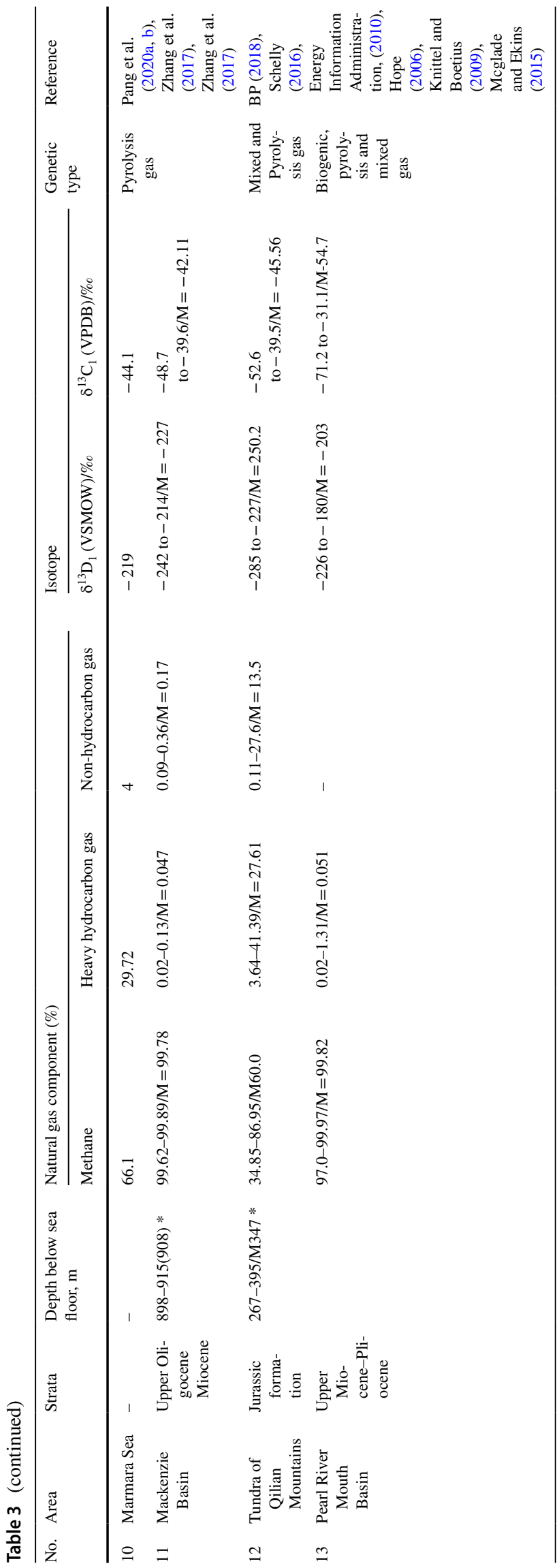

marine sediments would weaken slope stability, leading to submarine landslides, triggering earthquakes and tsunamis (Knittel and Boetius 2009). The increasing temperature of the earth caused by the massive oil and gas consumption is much higher than we once estimated, and it is necessary to drastically reduce it to be compatible with a global warming limit of $2^{\circ} \mathrm{C}$ (Mcglade and Ekins 2015). Meanwhile, the exploitation cost for the NGH is extremely high and the technology is not yet mature. All of these are unfavorable for the NGH exploitation. It is emphasized here that as a kind of fossil energy, NGH is unlikely to replace conventional and unconventional oil and gas under current conditions, but it does not mean that this kind of resource will not be used on a large scale in the future. As human beings continue to search for renewable energy and make a transition to low carbon economy, the coal, oil, natural gas and NGH may be continuously exploited and utilized on a large scale as the main chemical materials or other valuable raw materials in the future.

\section{Conclusion}

There are at least 29 estimates of global NGH resource in the literature, and their variation over time records how our perceptions with respect to its potential resource change with increasing knowledge. Based on the statistical model, projecting the trend into future time could provide insights for repositioning the NGH in the future global energy resource system, and the global NGH resource cannot be predicted by the current or previous estimated values.

From the trend model, the global potential TRR of NGH will decrease gradually in next 30 years. It is projected to be $41 \times 10^{12} \mathrm{~m}^{3}$ at 2050 , accounting for $3.2 \%$ of the global conventional oil and gas resource, which is consistent with the $1.6 \%-4.4 \%$ from volumetric approach and $1.1 \%-3.4 \%$ from matter balance approach, and can only support human society for less than 8 years based on the current energy consumption level.

In addition to much reduced potential resource estimates, technical challenges and high cost in commercial production, environmental risks and lack of competitive advantage against fast growing unconventional and renewable resources suggest that NGH resource will be difficult to replace conventional oil and gas resources and become major energy source in the future.

Acknowledgements This research was financially supported by the CAS consultation project (Grant number-2019-ZW11-Z-035) and the National Basic Research Program of China (973) (Projects: 2006CB202300, 2011CB201100) and China High-Tech R\&D (863) Program Project (2013AA092600). We would like to thank Gao Deli, Academician of Chinese Academy of Sciences, for his comments and recommendation in publishing this paper in Petroleum Science. 

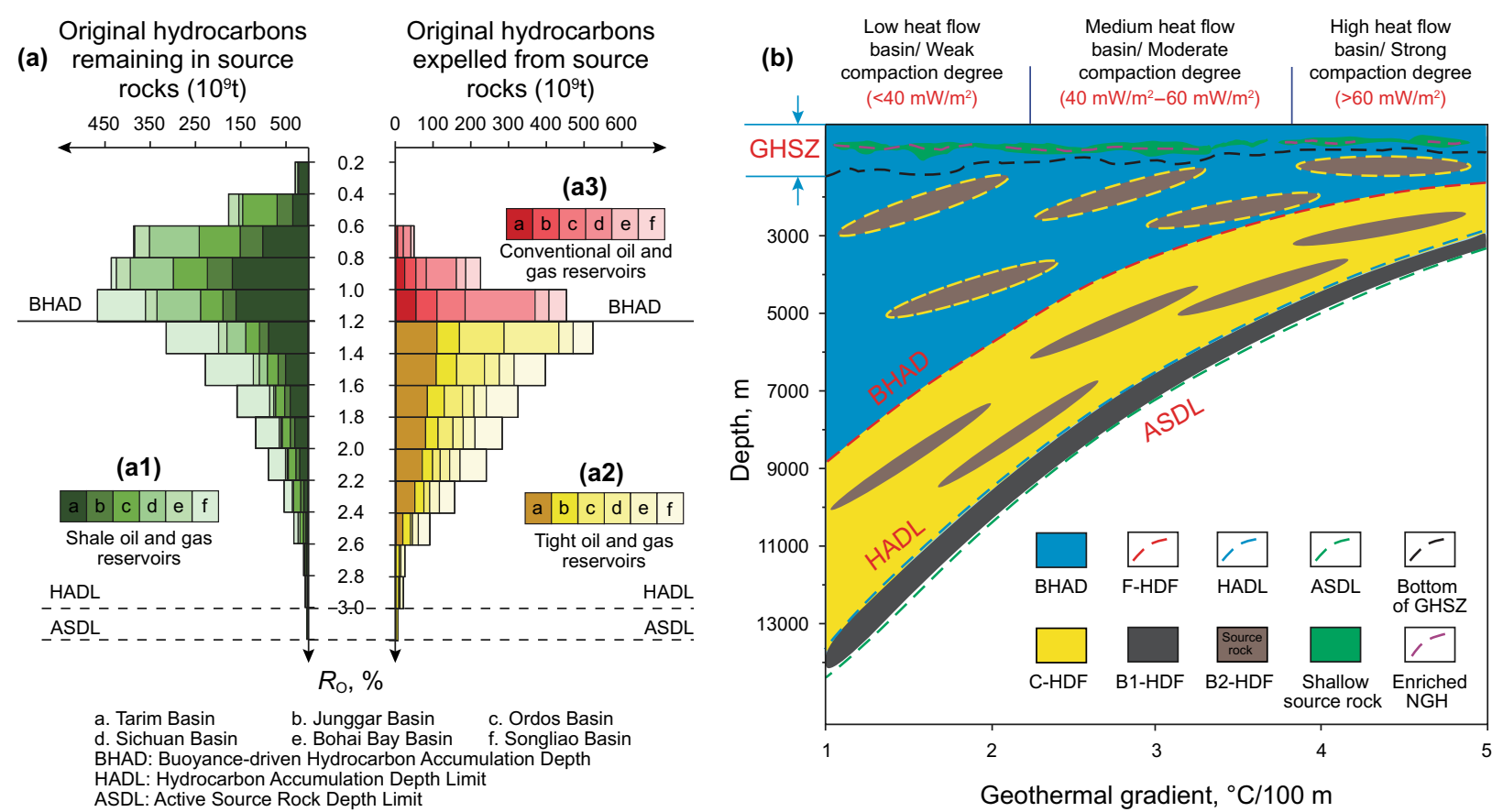

Fig. 7 Formation and distribution model of oil and gas resources controlled jointly by hydrocarbon thresholds and dynamic fields in petroliferous basins. a hydrocarbon thresholds controlling the distribution hydrocarbon generation and expulsion from source rocks in six representative petroliferous basins in China: hydrocarbons retained in source rocks (a1); hydrocarbons expelled above BHAD (a2). Hydrocarbons expelled under the BHAD (a3). b Dynamic boundaries and dynamic fields jointly controlling the formation and distribution of different oil and gas resources: free hydrocarbon dynamic field (F-HDF, blue) controlling conventional oil and gas; confined hydrocarbon dynamic fields (C-HDF, yellow) controlling tight oil and gas; bound hydrocarbon dynamic field (B2-HDF, gray) controlling shale oil and gas. Gas hydrate stable zone (GHSZ, top of F-HDF) controlling NGH resources

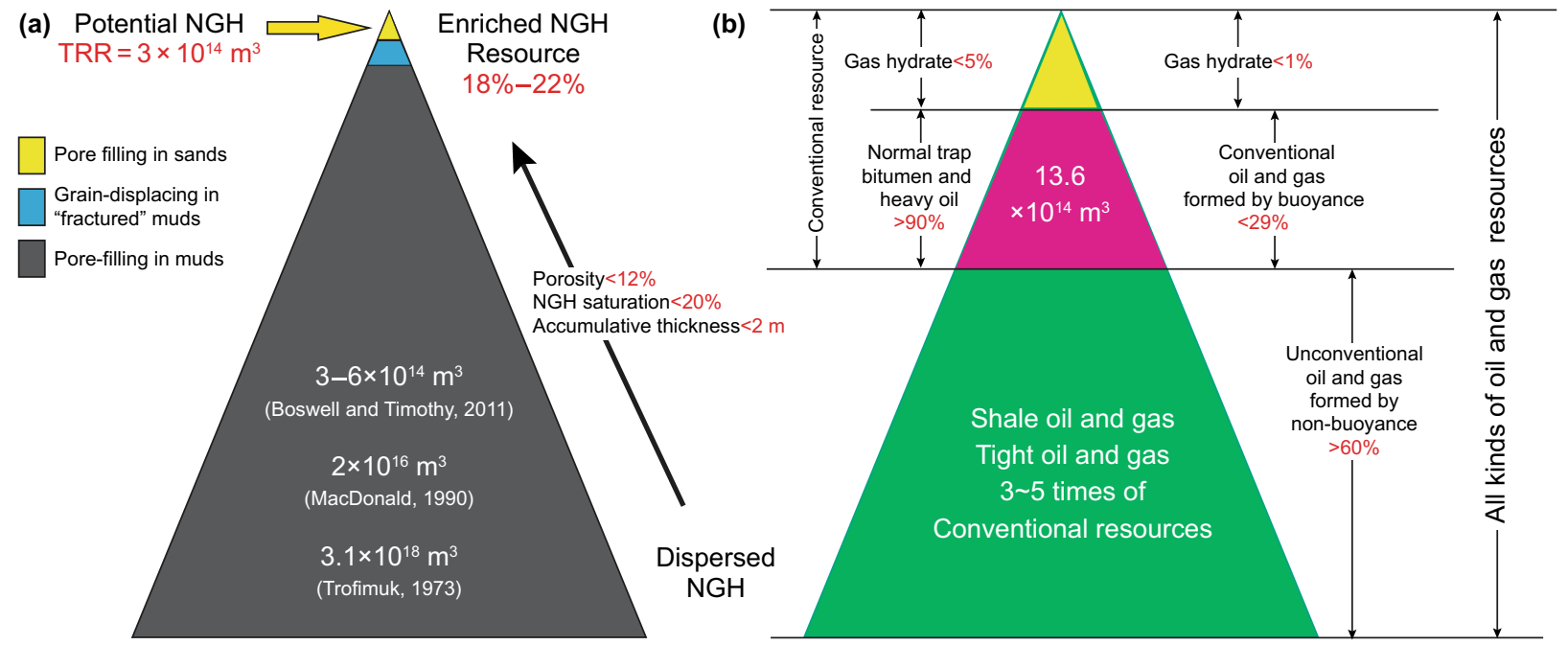

Fig. 8 Global NGH resource and its relative amount. a Estimated TRR of NGH resource and its relative amount in the total global estimated NGH amount in place (modified from Boswell 2009; Boswell and Collett 2011); b estimated global NGH resource, its relative amounts in both the total global conventional resource and the total global conventional and unconventional resources 
Table 4 Global resource in place and technically recoverable resource of NGH estimated by three methods and their comparison

\begin{tabular}{|c|c|c|c|c|}
\hline Estimate methods & $\begin{array}{l}\text { Trend analysis } \\
\text { (mode value) }\end{array}$ & $\begin{array}{l}\text { Volumetric (aver- } \\
\text { age, mode) }\end{array}$ & Matter balance (average) & $\begin{array}{l}\text { Comprehensive } \\
\text { (average, mode) }\end{array}$ \\
\hline $\mathrm{RIP}, \times 10^{12} \mathrm{~m}^{3}$ & 148.2 & $64.5-184.7 *$ & $44.0 *-134.8 *$ & 115.2 \\
\hline $\mathrm{TRR}, \times 10^{12} \mathrm{~m}^{3}$ & 41.46 & $22-63$ & $15-46$ & $15-63$ \\
\hline Ratios of NGH TRR to total conventional, $\%$ & 3.2 & $1.6-4.4$ & $1.1-3.4$ & $1.1-4.4$ \\
\hline Sustainable time at current consumption, years & 5.5 & $2.9-8.3$ & $2.0-6.0$ & $2.0-8.3$ \\
\hline Remarks about calculations & \multicolumn{4}{|c|}{$\begin{array}{l}\text { The TRR of global conventional oil and gas resource }\left(\times 10^{12} \mathrm{~m}^{3} \text { gas equivalent) is }\right. \\
\text { 1362.0, including normal oil 595.0, normal gas } 470.5 \text { and bitumen } 296.5 \text {, data from } \\
\text { the literature (Zou et al. 2015); the global oil and gas consumption level of } 7.6 \times 10^{12} \\
\mathrm{~m}^{3} \text { gas equivalent in } 2017 \text { (BP 2018) }\end{array}$} \\
\hline
\end{tabular}

Number with * extrapolated from other data

Open Access This article is licensed under a Creative Commons Attribution 4.0 International License, which permits use, sharing, adaptation, distribution and reproduction in any medium or format, as long as you give appropriate credit to the original author(s) and the source, provide a link to the Creative Commons licence, and indicate if changes were made. The images or other third party material in this article are included in the article's Creative Commons licence, unless indicated otherwise in a credit line to the material. If material is not included in the article's Creative Commons licence and your intended use is not permitted by statutory regulation or exceeds the permitted use, you will need to obtain permission directly from the copyright holder. To view a copy of this licence, visit http://creativecommons.org/licenses/by/4.0/.

\section{References}

Annual energy review 2009. Energy Information Administration, 2010. doi: https://doi.org/10.2172/1212313

Archer D, Buffett B, Brovkin V, et al. Ocean methane hydrates as a slow tipping point in the global carbon cycle. Proc Natl Acad Sci USA. 2009;106(49):20596-601. https://doi.org/10.1073/pnas. 0800885105

Arthur HJ. Global Resource Potential of Gas Hydrate. 2011 AAPG Annual Convention and Exhibition, April 10-13, Houton, Texas, USA

Booth JS, Rowe MM, Fischer KM. Offshore gas hydrate sample database with an overview and preliminary analysis: U.S. Geological Survey. 1996.

Boswell R, Collett TS. Current perspectives on gas hydrate resources. Energ Environ Sci. 2011;4:1206-15. https://doi.org/10.1039/ c0ee00203h.

Boswell R. Is Gas Hydrate Energy Within Reach? Science. 2009;325:957-8. https://doi.org/10.1126/science.1175074.

BP, Statistical Review of World Energy 2017, 2018.

Buffett B, Archer D. Global inventory of methane clathrate: sensitivity to changes in the deep ocean. Earth Planet Sci Lett. 2004;227(34):185-99. https://doi.org/10.1016/j.epsl.2004.09.005.

Burwicz B, Rüpke LH, Wallmann K. Estimation of the global amount of submarine gas hydrates formed via microbial methane formation based on numerical reaction-transport modeling and a novel parameterization of Holocene sedimentation. Geochim Cosmochim Acta. 2011;75(16):4562-76. https://doi.org/10.1016/j.gca. 2011.05.029.

Chong ZR, Yang SHB, Babu P, et al. Review of natural gas hydrates as an energy resource: Prospects and challenges. Appl Energy. 2016;162:1633-52. https://doi.org/10.1016/j.apenergy.2014.12. 061.
Cong XR, Wu NY, Su M, et al. New progress and outlook of potential resources volume of natural gas hydrate. Adv New Renewable Energy. 2014;6:462-70. https://doi.org/10.3969/j.issn.2095-560X. 2014.06.009 (inChinese).

Dai JX, Ni YY, Huang S. Genetic types of gas hydrates in China. Oil and gas Explor Develop. 2017;44:837-48 (in Chinese).

Dallimore SR, Collett TS, Taylor AE, et al. Scientific Results from JAPEX/JNOC/GSC et al. Mallik 5L-38 Gas Hydrate Production Research Well, Mackenzie Delta, Northwest Territories, Canada. Geological Survey of Canada. 2005; Bulletin 585.

Dickens GR, Paull CL, Wallace P. Direct measurement of in situ methane quantities in a large gas-hydrate reservoir. Nature. 1997;385(6615):426-8. https://doi.org/10.1038/385426a0.

Dickens GR. The potential volume of oceanic methane hydrates with variable external conditions. Org Geochem. 2001;32(10):117993. https://doi.org/10.1016/s0146-6380(01)00086-9.

Falenty A, Hansen TC, Kuhs WF. Formation and properties of ice XVI obtained by emptying a type sII clathrate hydrate. Nature. 2014;516:231-3. https://doi.org/10.1038/nature14014.

Ge Q, Wang J, Xiang H. Marine gas hydrate resource estimation and environmental effect assessment. Marine Geol Quater Geol. 2005;24(4):127-33.

Gong YH, Zhang GX, Guo YQ, et al. Prospect of gas hydrate resources in the area to southwest Shen-Hu of northern south China Sea. Marine Geol Quater Geol. 2013;33:97-104 (in Chinese).

Gornitz V, Fung I. Potential distribution of methane hydrates in the world's oceans. Global Biogeochem cy. 1994;8(3):335-47. https://doi.org/10.1029/94gb00766.

Harvey DD, Huang Z. Evaluation of potential impact of methane clathrate destabilization on future global warming. J Geophys Res. 1995;100(D2):2905-26. https://doi.org/10.1029/94jd02829.

Holbrook WS, Hoskins H, Wood WT, et al. Methane hydrate and free gas on the blake ridge from vertical seismic profiling. Science. 1996;273(5283):1840-3. https://doi.org/10.1126/science. 273.5283 .1840

Hope . The marginal impacts of $\mathrm{CO} 2 \mathrm{CH} 4$ and SF6 emissions. Climate Policy. 2006;6:537-44. https://doi.org/10.2139/ssrn.424061.

Katsube TJ, Jonasson IR, Connell-Madore S, et al. Petrophysical characteristics of gas-hydrate-bearing and gas-hydrate-free formations in the JAPEX/JNOC/GSC et al. Mallik 5L-38 gas hydrate production research well. Geol Surv Canada Bull. 2005;585:140. https://doi.org/10.4095/220729.

Klauda JB, Sandler SI. Global distribution of methane hydrate in ocean sediment. Energy Fuels. 2005;19(2):459-70. https://doi. org/10.1021/ef049798o. 
Knittel K, Boetius A. Anaerobic oxidation of methane: progress with an unknown process. Annu Rev Microbiol. 2009;63:311-34. https://doi.org/10.1146/annurev.micro.61.080706.093130.

Konno Y, Fujii T, Sato A, et al. Key findings of the world's first offshore methane hydrate production test off the coast of Japan: toward future commercial production. Energ Fuel. 2017;31(3):2607-16. https://doi.org/10.1021/acs.energyfuels.6b03143.

Konno Y, Jin Y, Shinjou K, et al. Experimental evaluation of the gas recovery factor of methane hydrate in sandy sediment. RSC Adv. 2014;4:51666-75. https://doi.org/10.1039/c4ra08822k.

Kretschmer K, Biastoch A, Rüpke L, et al. Modeling the fate of methane hydrates under global warming. Global Biogeochem Cycles. 2015;29(5):610-25. https://doi.org/10.1002/2014gb005011.

Kvenvolden A. Methane hydrate-a major reservoir of carbon in the shallow geosphere. Chem Geol. 1988;71(1-3):41-51. https:// doi.org/10.1016/0009-2541(88)90104-0.

Kvenvolden A. Potential effects of gas hydrate on human welfare. Proc Natl Acad Sci USA. 1999;96(7):3420-6. https://doi.org/ 10.1073/pnas.96.7.3420.

MacDonald GJ. The future of methane as an energy resource. Ann Rev Energy. 1990;5:53-83. https://doi.org/10.1146/annurev.eg. 15.110190 .000413$.

Makogon YF. Hydrates of Hydrocarbons. Penn Well, Tulsa, OKLAHOMA, 504. 1997.

McClade C, Speirs J, Sorrell S. Unconventional gas-A review of regional and global resource estimates. Energy. 2013;55:571-84. https://doi.org/10.1016/j.energy.2013.01.048.

Mcglade C, Ekins P. The geographical distribution of fossil fuels unused when limiting global warming to $2{ }^{\circ} \mathrm{C}$. Nature. 2015;517:187-90. https://doi.org/10.1038/nature14016.

McIver RD. Gas hydrates. Long-Term Energy Resources MA. 1981; 713-726.

Milkov V, Clapool GE, Lee YJ, et al. In situ methane concentrations at hydrate ridge, offshore oregon: new constraints on the global gas hydrate inventory from an active margin. Geology. 2003;31(10):833-6. https://doi.org/10.1130/g19689.1.

Milkov V. Global estimates of hydrate-bound gas in marine sediments: how much is really out there? Earth-Sci Rev. 2004;66(3):183-97. https://doi.org/10.1016/j.earscirev.2003.11.002.

Ministry of Natural Resources of the People's Republic of China. http:// www.mlr.gov.cn/xwdt/jrxw/201711/t20171117_1674082.htm. 2017.

Nesterov II, Salmanov FK. Present and future hydrocarbon resources of the Earth's crust. Futur Supply Nature-Made Petrol Gas. 1977;5(5):185-92.

Ning F, Yu Y, Kjelstrup S, et al. Mechanical properties of Clathrate hydrate: status and perspectives. Energ Environ Sci. 2012;5:6779_ 95. https://doi.org/10.1039/c2ee03435b.

Osadetz KG, Chen Z. A re-examination of Beaufort Sea-Mackenzie Delta basin gas hydrate resource potential: oil and gas system approaches to non-conventional gas resource appraisal and geologically-sourced methane flux. Bull Canadian Oil Gas Geol. 2010;58(1):56-71. https://doi.org/10.2113/gscpgbull.58.1.56.

Pang XQ, Jia CZ, Zhang K, et al. The dead line for oil and gas and implication for fossil resource prediction. Earth Syst Sci Data. 2020a;12(1):577-90. https://doi.org/10.5194/essd-12-577-2020.

Pang XQ, Jia CZ, Chen JQ, et al. A unified model for the formation and distribution of both conventional and unconventional hydrocarbon reservoirs. Geosci Front. 2020b;12(2):695-711. https://doi.org/10. 1016/j.gsf.2020.06.009.

Pang XQ, Jia CZ, Wang WY, et al. Buoyance-driven hydrocarbon accumulation depth and its implication for unconventional resource prediction. Geosci Front. 2021. https://doi.org/10.1016/j.gsf.2020. 11.019.

Pang XQ, Li MW, Li SM, et al. Geochemistry of petroleum systems in the Niuzhuang South Slope of Bohai Bay Basin: Part 3 Estimating hydrocarbon expulsion from the Shahejie formation. Organic Geochemistry. 2005;36(4):497-510. https://doi.org/10.1016/j.orgge ochem.2004.12.001.

Piñero E, Marquardt M, Hensen C, et al. Estimation of the global inventory of methane hydrates in marine sediments using transfer functions. Biogeosciences. 2013;10(2):959-75. https://doi.org/10. 5194/bg-10-959-2013.

Sain K, Gupta H. Gas hydrates in India: potential and development. Gondwana Res. 2012;22:645-57. https://doi.org/10.1016/j.gr. 2012.01.007.

Schelly C. Unconventional oil and gas: The role of politics and proximity. Nature Energy. 2016;1(10):16163. https://doi.org/10.1038/ nenergy.2016.163.

Sloan E. Fundamental principles and applications of natural gas hydrates. Nature. 2003;426:353-9. https://doi.org/10.1038/nature02135.

Soloviev VA. Global estimation of gas content in submarine gas hydrate accumulations. Geol Geofiz. 2002;43(7):648-61.

Trofimuk AA, Cherskiy NV, Makogon UF. Possible gas reserves in continental and marine deposits and prospecting and development methods. Conventional and Unconventional World Natural Gas Resources. Proceedings of the Fifth II ASA Conference on Energy Resources. International Institute for Applied Systems Analysis. 1983; 1983b: 459-468.

Trofimuk AA, Cherskiy NV, Tsarev VP. Gas hydrates-new sources of hydrocarbons. Priroda. 1979;1:18-27.

Trofimuk AA, Cherskiy NV, Tsarev VP. The reserves of biogenic methane in the ocean. Dokl Akad Nauk SSSR. 1975;225:936-9.

Trofimuk AA, Cherskiy NV, Tsarev VP. Accumulation of natural gases in zones of hydrate-formation in the hydrosphere. Dokl Akad Nauk SSSR. 1973;212:931-4.

Tsarev VP, Cherskiy NV. Evaluation of the reserves in the light of search and prospecting of natural gases from the bottom sediments of the world's ocean. Geol Geofiz. 1977;5:21-31.

Wadham JL, Arndt S, Tulaczyk S, et al. Potential methane reservoirs beneath Antarctica. Nature. 2012;488:633-7. https://doi.org/10. 1038/nature11374.

Wallmann K, Pinero E, Burwicz E, et al. The global inventory of methane hydrate in marine sediments: a theoretical approach. Energies. 2012;5(7):2449-98. https://doi.org/10.3390/en5072449.

Wang XJ, Wu SG, Liu XW, et al. Estimation of gas hydrates resources based on well log data and seismic data in Shenhu area. Progress in Geophys. 2010;25:1288-97. https://doi.org/10.3969/j.issn. 1004-2903.2010.04.017 (in Chinese).

Xinhua net. The second round of marine gas hydrate production test has successful set additional new world records, http://www. xinhuanet.com/science/2020-03/27/c_138922044.htm.2020 (in Chinese).

Yang SX, Zhang M, Liang JQ, et al. Preliminary results of china's third gas hydrate drilling expedition: a critical step from discovery to development in the South China Sea. Fire Ice. 2015;15(2):1-21. https://doi.org/10.31035/cg2018029.

Zhang RW, Lu JA, Wen PF, et al. Distribution of gas hydrate reservoir in the first production test region of the Shenhu area. South China Sea China Geology. 2018;4:493-504. https://doi.org/10.31035/cg2018049.

Zhang W, Liang JQ, Lu JA, et al. Accumulation features and mechanisms of high saturation natural gas hydrate in Shenhu Area, northern South China Sea. Pet Explor Develop. 2017;44(5):67080. https://doi.org/10.11698/PED.2017.05.02 (in Chinese).

Zou CN, Zhai GM, Zhang GY, et al. Formation, distribution, potential, and prediction of global conventional and unconventional hydrocarbon resources. Pet Explor Dev+. 2015;42(1):14-28. https:// doi.org/10.1016/S1876-3804(15)60002-7. 